we making progress? [Letter]. Br J Gen Pract 2019; DOI: https://doi.org/10.3399/bjgp19X703853.

DOI: https://doi.org/10.3399/bjgp19X705053

\section{Raising the profile of academic general practice to our medical students}

Lamb and Alberti' highlight the disappointing figure that only $3 \%$ of medical students associate general practice with being an intellectually challenging career. ${ }^{2}$ I am a medical student in my penultimate year and am hoping to pursue a career in general practice that I believe will be stimulating, varied, and intellectually challenging.

So how have I come to be a part of this 3\%? Well, Lamb and Alberti are right that it is the result of experiencing high-level thinking in general practice. I have done a student-selected component in general practice; an intercalation involving general practice research; and I have attended general practice conferences. Having no preselected specialty when I arrived at medical school, I can truly say that my perspective is a result of this experience.

However, the suggestion that I can only be intellectually challenged in general practice by pursuing an academic training pathway is simply reinforcing the idea that general practice is not enough.

In 2011, Katerndahl et al demonstrated that the complexity of care delivered in the average general practice consultation was greater than the hospital specialties observed. ${ }^{3}$ The average consultation is built upon a multitude of theoretical principles (for example, continuity of care) that makes each encounter a significant academic challenge.

It is time that medical educators acknowledge the academic rigour of general practice itself and therefore teach, assess, and value the high-level thinking required to be a GP. I hope that all students can be given the opportunity to see general practice from this perspective, by making its principles a standard element of the curriculum rather than an added extra.

Molly Dineen,

Medical Student, University of Exeter/St Leonard's Practice, Exeter.

Email: mcd215daexeter.ac.uk

\section{REFERENCES}

1. Lamb El, Alberti H. Raising the profile of academic general practice to our medical students. $\mathrm{Br} J$
Gen Pract 2019; DOI: https://doi.org/10.3399/ bjgp19X704045

2. Royal College of General Practitioners, Medical Schools Council. Destination GP: medical students' experiences and perceptions of general practice. London: RCGP, 2017. https://www.rcgp. org.uk/policy/rcgp-policy-areas/destination-gp. aspx (accessed 9 Jul 2019).

3. Katerndahl D, Wood R, Jaén CR. Family medicine encounters are more complex than those in cardiology and psychiatry. J Am Board Fam Med $2011 ; \mathbf{2 4 ( 1 ) : ~ 6 - 1 5}$

DOI: https://doi.org/10.3399/bjgp19X705029

\section{Correction}

In Research by Nelson PA et al. Skill-mix change in general practice: a qualitative comparison of three 'new' non-medical roles in English primary care. Br J Gen Pract 2019; DOI: https://doi.org/10.3399/ bjgp19X704117, Box 1 had incorrect text in the second column, fifth bullet point. The text should read: Limited evidence suggests PAs may provide safe and effective care that is acceptable to patients and that for less medically complex patients, compared to care from a GP, PAs may not increase return visits, tests/prescriptions ordered or referrals made lalthough total costs of treatment are unknown); :" This has been corrected in the online version.

DOI: https://doi.org/10.3399/bjgp19X705041 